\title{
Modeling of liquid hydrocarbon products from syngas
}

\author{
Hossein Atashi ${ }^{1}$ (D) Mohsen Hajisafari ${ }^{1}$ Fatemeh Rezaeian $^{1}$ (D) \\ Mohammad Javad Parnian ${ }^{2}$
}

Received: 8 June 2018/Revised: 11 August 2018/Accepted: 4 December 2018/Published online: 21 December 2018

(C) The Author(s) 2018

\begin{abstract}
The modeling of hydrocarbon selectivity and $\mathrm{CO}$ conversion of the Fischer-Tropsch synthesis over Fe-Ni/ $\mathrm{Al}_{2} \mathrm{O}_{3}$ catalyst by using coupled artificial neural networks (ANN) and design of experiment (DOE) approaches were investigated. The variable parameters for modeling consisted of the pressure range between 2 and 10 bar and the temperature range of 523-573 K. After training of data by ANN and determination of DOE points by central composite design (CCD), the results were compiled together for producing simulated data used in the response surface method (RSM). The RSM was used as an applied mathematics model to demonstrate the $\mathrm{CO}$ conversion and selectivity of hydrocarbons dependence on the $\mathrm{CO}$ hydrogenation conditions. The results indicated that $\mathrm{CO}$ conversion and $C_{5}^{+}$selectivity increased with rising both temperature and pressure. The methane selectivity showed upward trend as the temperature increased. It also increased by decreasing pressure. Finally, the optimization of the catalytic process was carried out and conditions with maximum desired product were obtained. A comparison of experimental values and RSM values show that the RSM equations are able to predict the behavior of experimental data.
\end{abstract}

Keywords Fischer-Tropsch synthesis - Artificial neural network - Response surface method · CO conversion · Hydrocarbon selectivity

\section{Introduction}

Due to dwindling petroleum reserves and the fluctuations of the crude oil costs in the past few years, FischerTropsch synthesis (FTS) of syngas ( $\mathrm{CO}$ and $\mathrm{H}_{2}$ mixtures) has been considered as one of the foremost promising ways to provide ultra-clean fuels at an economically possible

Hossein Atashi

h.ateshy@hamoon.usb.ac.ir

Mohsen Hajisafari

mohsen.hajisafari@gmail.com

Fatemeh Rezaeian

ch.engineering87@gmail.com

1 Department of Chemical Engineering, University of Sistan and Baluchestan, Zahedan, Iran

2 School of Chemical Engineering, Iran University of Science and Technology, Tehran, Iran cost (Fu et al. 2013; Park et al. 2014). In FTS, which is a kind of polymerization process, a large range of light gases and distillates, including olefins, paraffins, and oxygenated compounds are produced from synthesis gas in a catalytic reaction (Parnian et al. 2014a, b; Liu et al. 2015). The synthetic fuel made from Fischer-Tropsch synthesis is characterized by a prime quality, significantly from the view point of low pollution and a high cetane number (Coronel-García et al. 2015; Rodríguez-Fernández et al. 2009). The spectrum of the FTS product contains the complex mixtures of linear and branched hydrocarbons ranging from light alkenes to heavy waxes and oxygenated products (Derevich et al. 2012; Todic et al. 2018; Najafabadi et al. 2016; van Helden et al. 2017; Khodakov et al. 2007). The most desired products are those with low methane, low alcohol, high alkene/alkane ratio, and high $C_{5}^{+}$content, which can be controlled by a modification of the catalyst, the reactor and the reaction conditions $(\mathrm{Fu}$ 
et al. 2013). Due to the complex nature of the synthesis, $\mathrm{CO}$ hydrogenation is faced with a basic problem of controlling the product selectivity, and this is closely related to the reaction mechanism and the behavior of reaction intermediates (van Helden et al. 2017). The most common catalysts for FTS are cobalt- or iron-based catalysts. Some inorganic supports with high surface area, such as silica and alumina, have been used to increase the active phase dispersion (Khodakov et al. 2007; Ralston et al. 2017).

The use of Fe-based catalysts on FTS has been studied by many investigators and was shown to possess satisfactory performances within the production of liquid fuels and waxes, particularly at high pressures. Most studies with iron catalysts have targeted on reaction conversion, overall rates of reaction and also on the product distribution over some catalyst compositions. In many reported literatures, the use of $\mathrm{Ni}$ as promoter not only has resulted in increasing light hydrocarbons, but it also has caused heavy hydrocarbons to decrease. The use of bimetallic is more common compared to pure metal catalysts ( $\mathrm{Li}$ et al. 2014). Ishihara et al. (1987) exhibited the higher activity of bimetallic $\mathrm{Fe}-\mathrm{Ni}$ in comparison with $\mathrm{Fe}$ and $\mathrm{Ni}$ catalyst. In a bid to achieve a better knowledge of the FTS, some studies were conducted to understand the effects of operating conditions and different catalyst promoters on the distribution of the FTS products. These studies have demonstrated that iron-based catalysts produced paraffins, particularly paraffins and olefins with low molecular weight, depending on the reaction conditions used and the kind of catalysts and reactors used (Farias et al. 2008; Feyzi et al. 2015; Peña et al. 2018). Although there are a lot of kinetic expressions for $\mathrm{CO}$ consumption in literature, the one which focuses on the prediction of hydrocarbon selectivity is hardly found. A challenge facing contemporary FTS research is the development of techniques for controlling process parameters, such as selectivity on liquid products, productivity of the catalytic bed, the yield of specific groups of hydrocarbons, etc. (Zhang et al. 2014; Bashiri et al. 2018; Savost'yanov et al. 2018; Challiwala et al. 2018). Articles about product selectivity are reported qualitatively, while no article has been presented the model which can predict what will happen with manipulating the operating conditions (Sun et al. 2018; Yang et al. 2010; Cheng et al. 2018).

In this work, the methodologies of design of experiment (DOE) and ANN were used for selectivity modeling of the hydrocarbon products and $\mathrm{CO}$ conversion. For selectivity modeling by RSM, the simulation of DOE data is of necessity; therefore ANN was used to produce these data from the experimental data. The RSM was used to determine the exact optimum point for maximum $C_{5}^{+}$, minimum $\mathrm{CH}_{4}$ distribution in products and maximum $\mathrm{CO}$ conversion in the range of the temperature and the pressure. This method can be applied to calculate the product selectivity and $\mathrm{CO}$ conversion for any temperature and pressure within the experimental condition ranges. Furthermore this method is very helpful in different industries to increase preferable products and also to decrease undesirable ones by manipulating operating conditions.

\section{Experimental}

Mirzaei et al. (2012) attempted to obtain the experimental data from fixed bed micro reactor. The catalyst was prepared by co-precipitation method. The molar ratio of the solution $\mathrm{Fe} / \mathrm{Ni}$ was $40 / 60$. The catalyst $\left(\mathrm{Fe}-\mathrm{Ni} / \mathrm{Al}_{2} \mathrm{O}_{3}\right)$ was dried at $383.15 \mathrm{~K}$ for $16 \mathrm{~h}$ and calcined at $873.15 \mathrm{~K}$ in flowing air for $6 \mathrm{~h}$ at $5{ }^{\circ} \mathrm{C} / \mathrm{min}$ the catalyst was used under reaction conditions of Fischer-Tropsch synthesis. Experimental data were obtained in 54 runs (Mirzaei et al. 2012).

\section{Modeling method}

With a variety of statistical tools available, the response surface methodology is an efficient procedure in scientific studies. This methodology is an assortment of statistical techniques for the experimental design, the building of the models, evaluating the consequences of factors, and searching for the optimum conditions. Using the experimental designs of response surface methodology makes it attainable to use statistical tools for the modeling (Shojaeimehr et al. 2014; Atashi and Rezaeian 2017).

In order to evaluate the behavior of product selectivity and $\mathrm{CO}$ conversion with temperature and pressure and also to determine the optimum range of operational condition (pressure and temperature), in which selectivity of desired products $\left(C_{5}^{+}\right)$was maximized and undesired products $\left(\mathrm{CH}_{4}\right)$ was minimized, modeling was necessary. In the reference experimental work (Mirzaei et al. 2012), CO conversion or products selectivity were reported in limited points such as $T: 563,573 \mathrm{~K} \ldots$, and $P: 2,3,4$ bar...hence, it was impossible to determine the $\mathrm{CO}$ conversion or products selectivity from unseen points. Therefore, modeling becomes an asset in determining the exact $\mathrm{CO}$ conversion or products selectivity for any temperature or pressure such as $547 \mathrm{~K}$ or $3.5 \mathrm{bar}$, and also to demonstrate the interaction between the parameters. Moreover, in order to develop RSM models, it is necessary to collect experimental data based on the DOE methods. In the reference work (Mirzaei et al. 2012), experimental data were not collected by DOE methods. To compensate for this drawback, ANNs in which original data were trained to produce 
appropriate input data for RSM were constructed. Then, RSM was used for the selectivity and CO conversion modeling.

\subsection{Artificial neural networks and design of experiment}

From chemical engineering viewpoint, selectivity studies play a significant role in achieving an optimum performance of FTS process. As an effective tool for organization of the experimental studies, designing of experiments (DOE) is widely used in various science and technology fields, as well as designing, optimizing and developing of the catalyst (Atashi and Rezaeian 2017; Atashi et al. 2015). In the last few years ANN based modeling helped to develop empirical models and also achieve better statistical analysis on experimental data (Nasr et al. 2013). ANN is a colossal structure of interconnected networks consisting of numerous individual elements called neurons, capable of performing parallel computations for data processing. Hence without having any prior knowledge about individual functional relationships, ANN can handle multiple independent and dependent variables simultaneously (Pirdashti et al. 2013).

In this work, three feed-forward networks with two input-single output neuron structures were constructed. The reactor operating conditions represented by the two inputs are temperature $(523-573 \mathrm{~K})$ and pressure (2-10 bar). The single output neuron of each of the three networks, respectively represented the following quantities, Network I: $\mathrm{CO}$ conversion, Network II: $\mathrm{CH}_{4}$ selectivity and Network III: $C_{5}^{+}$selectivity. The number of neurons in the hidden layer must be selected in order for the best fit of experimental data to be achieved. Therefore for the first network, the optimal number of hidden neurons was found to be 8 whereas for both Networks II and III, the corresponding numbers were 6 .

\subsection{Producing simulated data}

In the range of operating condition, a Central Composite Design (CCD) in software with two factors, pressure and temperature, was employed to create DOE points. With the use of the designed points from $\mathrm{CCD}$ and the trained networks, simulated outputs were generated in MATLAB. The simulated data were used to obtain the CO conversion and selectivity models by the adoption of response surface methodology.

\subsection{Response surface methodology}

The $\mathrm{CO}$ conversion, $\mathrm{CH}_{4}$, and $\mathrm{C}_{5}^{+}$selectivities data which were generated from MATLAB by using the neural networks and DOE points from CCD (Table 1), were analyzed using the RSM. The quadratic equation for the variable is as follows:

$Y=\beta_{0}+\sum \beta_{i} X_{i}+\sum \beta_{i i} X_{i}^{2}+\sum_{i} \sum_{j} \beta_{i j} X_{i} X_{j}$

where $Y$ is the predicted response; $\beta_{0}$ is a constant; $\beta_{i}$ is the first-order model coefficient; $\beta_{i i}$ is the squared coefficient for the factor $i$, and $\beta_{i j}$ is the linear model coefficient for the interaction between factors $i$ and $j . X_{i}$ is the value of the main effect according to the following:

$X_{i}=\frac{x_{i}-x_{i}^{*}}{\Delta x_{i}}$

where $X_{i}$ is the value of the $i$ th independent variable, $x_{i}$ is the un-coded value of the $i$ th independent variable, $x_{i}^{*}$ is the un-coded value of the $i$ th independent variable at the center point and, $\Delta x_{i}$ is the step change value.

All statistical analysis was done by DESIGN EXPERT software. The purpose was to study the potential of ANN simulated data in selectivity study and the capability of RSM in prediction of $\mathrm{CO}$ conversions, $\mathrm{CH}_{4}$ and $\mathrm{C}_{5}^{+}$ selectivities, as well as optimum condition.

The following statistics were applied for selectivity modeling of evaluating the quality of linear and nonlinear regression.

The correlation coefficient,

$R^{2}=1-\frac{\sum_{i=1}^{n}\left(y_{i, \mathrm{obs}}-y_{i, \mathrm{model}}\right)^{2}}{\sum_{i=1}^{n}\left(y_{i, \mathrm{obs}}-\bar{y}\right)^{2}}$

Adjusted $R^{2}$ :

$R_{\text {adj }}^{2}=1-\frac{\left(1-R^{2}\right)(n-1)}{n-m}$

Mean Absolute Relative Residual, MARR:

$\operatorname{MARR}=\sum_{i}^{n}\left|\frac{y_{i, \text { obs }}-y_{i, \text { model }}}{y_{i, o b s}}\right| \frac{1}{n} \times 100$

Relative Variance, $S_{\text {rel }}$ :

$S_{\text {rel }}=\left(\sum_{i}^{n}\left(\frac{y_{i, \text { obs }}-y_{i, \text { model }}}{y_{i, \text { obs }}}\right)^{2} \frac{1}{n-m}\right)^{0.5} \times 100$

Root mean of standard deviation (RMSD):

$R M S D=\frac{1}{n}\left(\sum_{i}^{n}\left(y_{i, \text { obs }}-y_{i, \text { model }}\right)^{2}\right)^{2}$ 
Table 1 DOE points and simulated outputs

\begin{tabular}{llllcc}
\hline Run & Temperature $(\mathrm{K})$ & Pressure (bar) & CO conversion $(\%)$ & $\mathrm{CH}_{4}$ selectivity $(\%)$ & $C_{5}^{+}$Selectivity $(\%)$ \\
\hline 1 & 560.5 & 4 & 38.8019 & 16.6795 & 17.2248 \\
2 & 523 & 6 & 32.4455 & 5.838 & 22.6338 \\
3 & 535.5 & 8 & 50.0707 & 2.1357 & 29.281 \\
4 & 548 & 10 & 66.7194 & 2.0618 & 37.4899 \\
5 & 548 & 6 & 38.9618 & 4.7775 & 21.7747 \\
6 & 560.5 & 8 & 70.0507 & 10.7472 & 34.5375 \\
7 & 573 & 6 & 77.1163 & 13.1052 & 32.5396 \\
8 & 548 & 6 & 38.9618 & 4.7775 & 21.7747 \\
9 & 548 & 6 & 38.9618 & 4.7775 & 21.7747 \\
10 & 548 & 6 & 38.9618 & 4.7775 & 21.7747 \\
11 & 535.5 & 4 & 20.2642 & 3.9305 & 11.1371 \\
12 & 548 & 2 & 18.1717 & 4.1837 & 7.3244 \\
13 & 548 & 6 & 38.9618 & 4.7775 & 21.7747 \\
\hline
\end{tabular}

where, $y_{i, \mathrm{obs}}$ is experimental point, $y_{i \text {,model }}$ is calculated point, $n$ is the number of observations and, $m$ is the number of parameters.

F-regression statistic and F-lack of fit are as follows:

$F-$ regression $=\frac{\mathrm{MSR}}{\mathrm{MSE}}$

$F-$ lack of fit $=\frac{\mathrm{MSLF}}{\mathrm{MSPE}}$

where MSR, MSE, MSLF and MSPE are Mean Sum of Regression, Mean Square Error, Mean Square Lack of Fit and Mean Square Pure Error, respectively (Atashi and Rezaeian 2017; Atashi et al. 2015).

\section{Results and discussion}

\subsection{Artificial neural networks (ANN)}

The temperature and pressure as inputs and $\mathrm{CO}$ conversion and product selectivity as targets were presented to the system. Estimation was made and the results were compared with the corresponding desired value. In order to test and validate the trained network, another two sets of data were used and the outputs were obtained. The outputs of the ANNs were compared with the experimental data for the trained, test and validation data sets, respectively. The results for the $\mathrm{CO}$ conversion, $\mathrm{CH}_{4}$, and $\mathrm{C}_{5}^{+}$selectivity networks are shown in Figs. 1, 2 and 3, respectively.

Figures 1, 2 and 3 are indicative of the relationship between targets (experimental data) and outputs (ANN data). As can be seen, the prediction of ANN was almost fitted to the experimental value. The high values of $R^{2}$
(0.96-0.99) were obtained, which indicated that the constructed neural networks can simulate the experimental domains very well. The excellent estimation performances obtained by using the trained networks demonstrated that the trained networks were reliable, accurate and hence could be employed further in the study.

\subsection{Response surface methodology (RSM)}

On the basis of RSM, the effect of temperature and pressure on $\mathrm{CO}$ conversion, methane, and $C_{5}^{+}$selectivity was studied and interactions between parameters were achieved. The regression equations for each variable were obtained after applying RSM, according to the temperature and pressure. The significance of each coefficient was determined by $F$ and $P$ values, and the statistically important terms presented in Table 2. The second order of regression models were reduced by omitting the terms which are unimportant. The analysis of variance was employed to test the significance of the ratio of mean square due to regression and mean square due to residual error. Generally, $P$ values lower than 0.05 indicated that the model was considered to be significant at the $95 \%$ confidence level.

Table 2 presents the RSM models for CO conversion, $\mathrm{CH}_{4}$, and $C_{5}^{+}$selectivity as well as their $R^{2}$ values. The $R^{2}$ values of the predicted model equations were quite high (98\%-99\%) and these values indicated that the RSM was sufficient enough in properly explaining the selectivity modeling of products and $\mathrm{CO}$ conversion.

After determination of the RSM models, 3D surface and contour plots were depicted to show the behavior trend of the targets and then multi-component optimization was 
Training: $\mathrm{R}=0.9973$

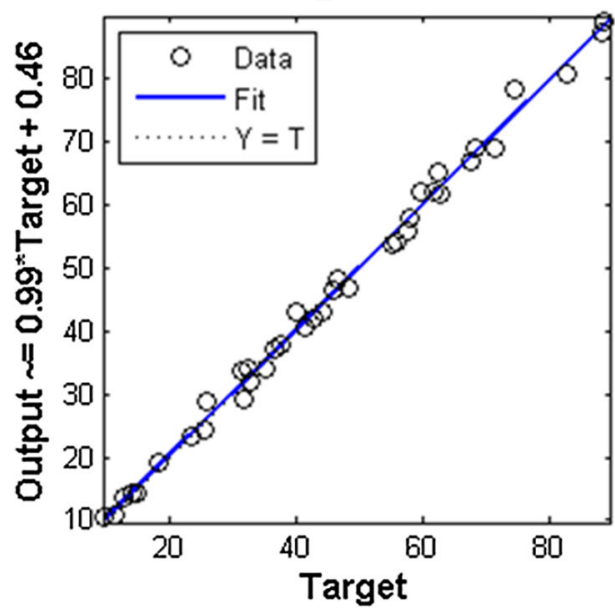

Test: $\mathrm{R}=0.98892$

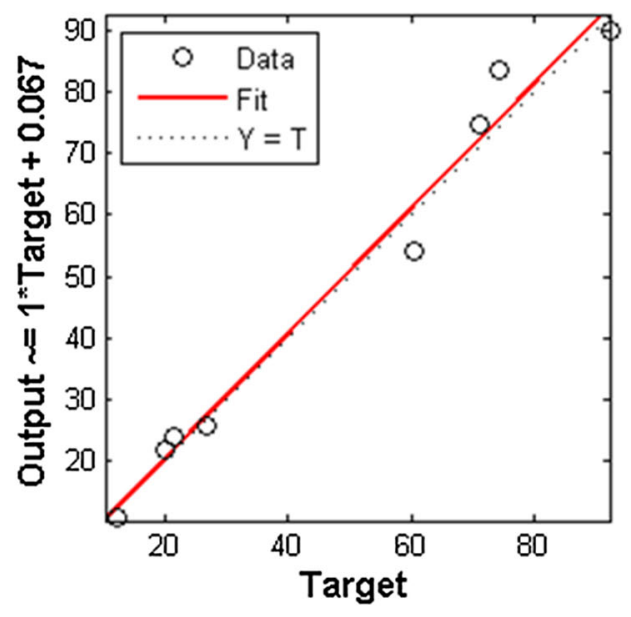

Fig. 1 Trained network for CO conversion data

established, considering the interactions between parameters in all the range of operating conditions to gain optimum point where $C_{5}^{+}$and $\mathrm{CO}$ conversion were maximized and $\mathrm{CH}_{4}$ was minimized.

Also, the RSM models in coded version can be used. The larger regression coefficient for the independent parameters demonstrated the stronger effect they possess on the responses. The equations presented in Table 3 cannot be used instead of the equations of Table 2. In other words, in order to calculate the $\mathrm{CO}$ conversion, $\mathrm{CH}_{4}$ or $\mathrm{C}_{5}^{+}$ selectivity at any point in the range of experimental conditions, only the RSM models in Table 2 can be applied.

According to the statistical analysis, temperature and pressure and their quadratic terms demonstrated the statistically significant effect on CO conversion. It is evident from the RSM models in Table 3 that the pressure has the greatest effect on $\mathrm{CO}$ conversion and $C_{5}^{+}$selectivity. However, the effect of the temperature on $\mathrm{CH}_{4}$ selectivity
Validation: $\mathrm{R}=0.96872$

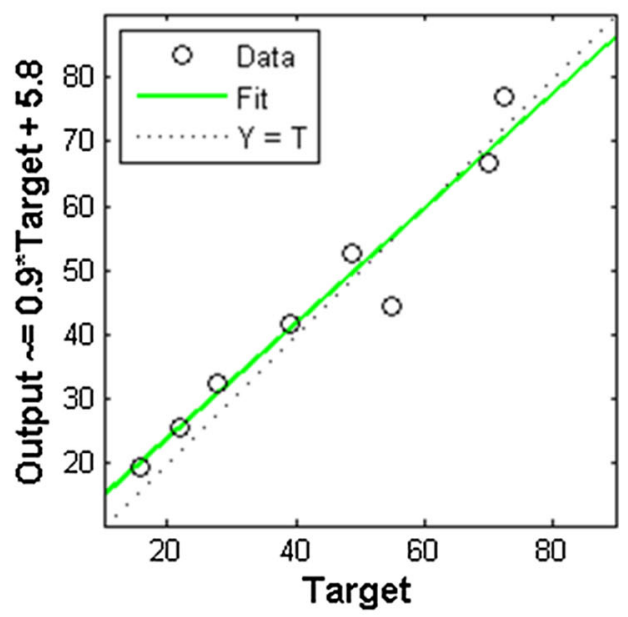

All: $\mathrm{R}=0.99149$

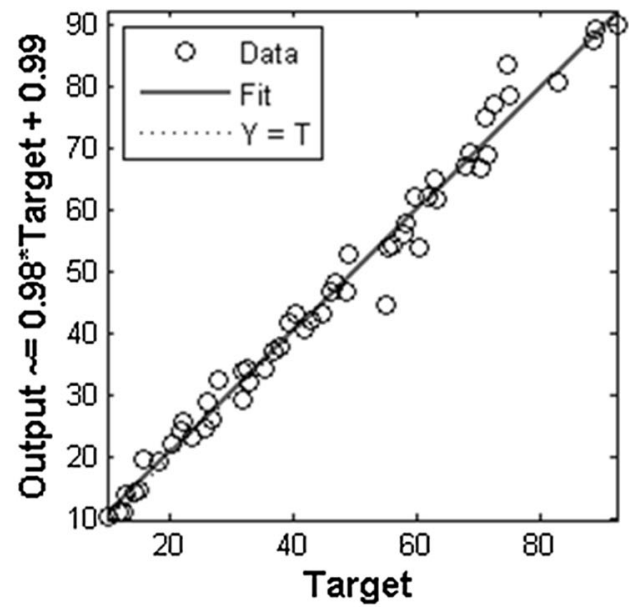

is stronger than the pressure. As the models indicate, the interaction between temperature and pressure is dimmed due to negligible impact on the model. The interaction between temperature and pressure did not display any statistical significance.

The contour plots (Figs. 4, 5, 6a) and 3D surface plots (Figs. 4, 5, 6b) clearly showed the dependency of $\mathrm{CO}$ conversions and product selectivity on temperature and pressure. The red dots on the contour plots showed the DOE points. Therefore, the ANN/RSM approach may be useful for efficient demonstration of the behaviors.

Figure 4 shows the surface plots and the contour of the $\mathrm{CO}$ conversion. Temperature and pressure exhibited an increasing effect on $\mathrm{CO}$ conversion; however, in high temperatures $(543-573 \mathrm{~K})$, this increasing effect of temperature changed. As the surface and contour plot has shown, by increasing both temperature and pressure the $\mathrm{CO}$ conversion raised. The surface plot and regression 
Training: $\mathrm{R}=0.99821$

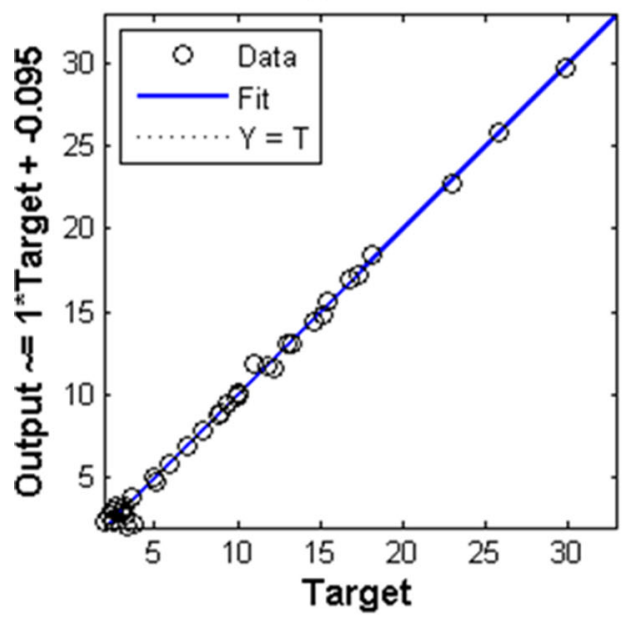

Test: $\mathrm{R}=0.99296$

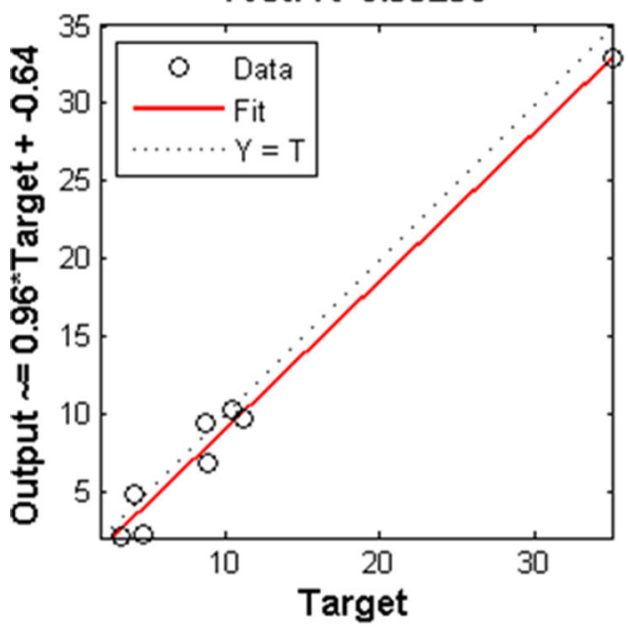

Validation: $\mathrm{R}=0.99613$

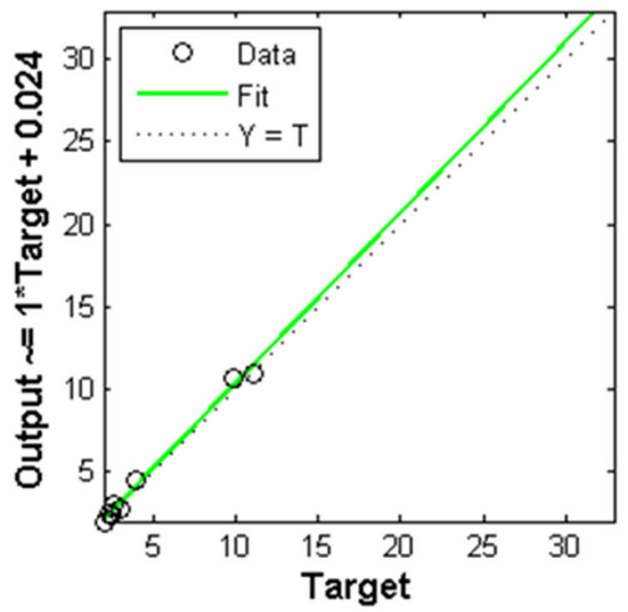

All: $\mathrm{R}=0.9954$

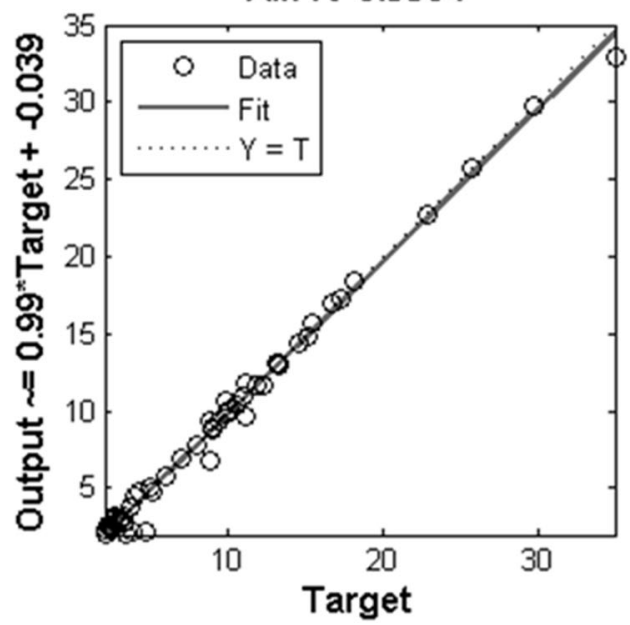

Fig. 2 Trained network for $\mathrm{CH}_{4}$ selectivity data

coefficients of the $\mathrm{CO}$ conversion equation in Table 3 indicated that pressure demonstrated a more significant effect than temperature.

Figure 5 shows the variation of $\mathrm{CH}_{4}$ selectivity with reaction conditions as contour and surface plots. $\mathrm{CH}_{4}$ selectivity generally demonstrates a decreasing trend with an increase in reactor pressure at any temperature. However, in low to moderate temperatures (523-543 K), $\mathrm{CH}_{4}$ selectivity maintained a constant value and in moderate to high temperatures $(543-573 \mathrm{~K})$ this value increased with increase in temperature. Generally by decreasing temperature and increasing pressure the minimum amount of $\mathrm{CH}_{4}$ selectivity occurs.

The change in $C_{5}^{+}$selectivity with operating conditions (temperature and pressure) plotted as contour and surface curves are shown in Fig. 6. According to the figure, $C_{5}^{+}$ selectivity increased with the increase in pressure at any temperature. From low to moderate temperature, the selectivity remained approximately constant while an obvious increasing trend occurred at moderate to high temperatures. As can be seen, the maximum selectivity was occurred by increasing pressure and temperature.

\subsection{Optimization}

Optimization plays an important role in statistical modeling where in order to maximize desired products, detecting the best operating condition is a requirement. In this research, multi-component optimization was used and the optimum point which facilitated the obtaining of desired results was achieved. Temperature (around $558 \mathrm{~K}$ ) and pressure (around 8 bar) resulted in maximized $\mathrm{CO}$ conversion and $C_{5}^{+}$selectivity and minimized $\mathrm{CH}_{4}$ selectivity simultaneously. 
Training: $\mathrm{R}=0.98522$

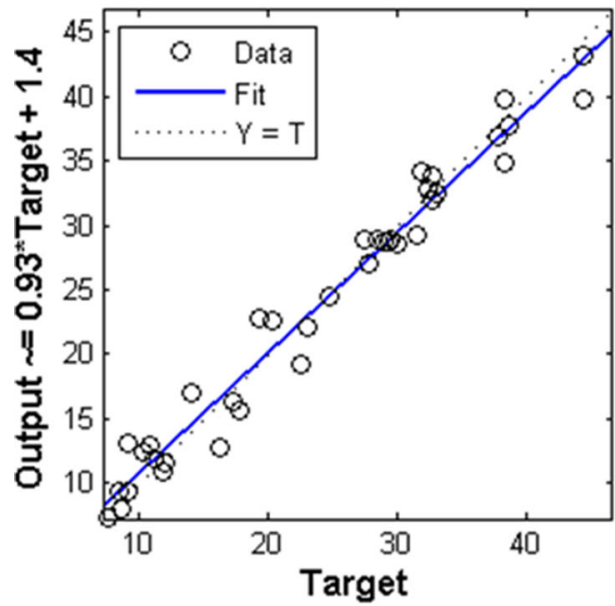

Test: $\mathbf{R}=0.99088$

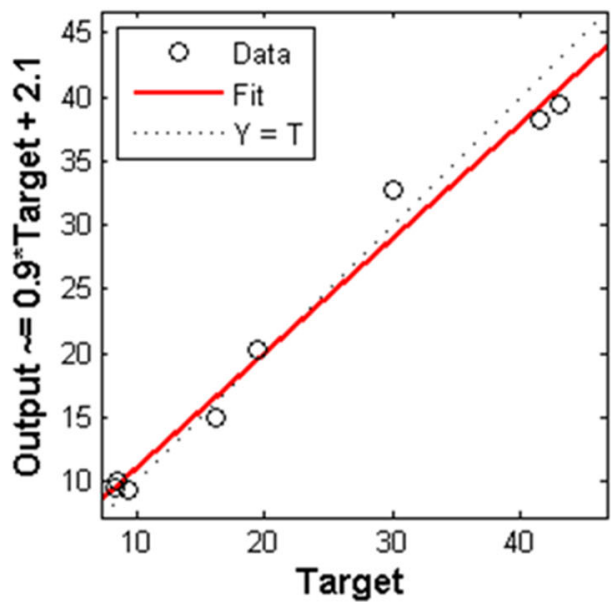

Validation: $\mathrm{R}=0.99618$

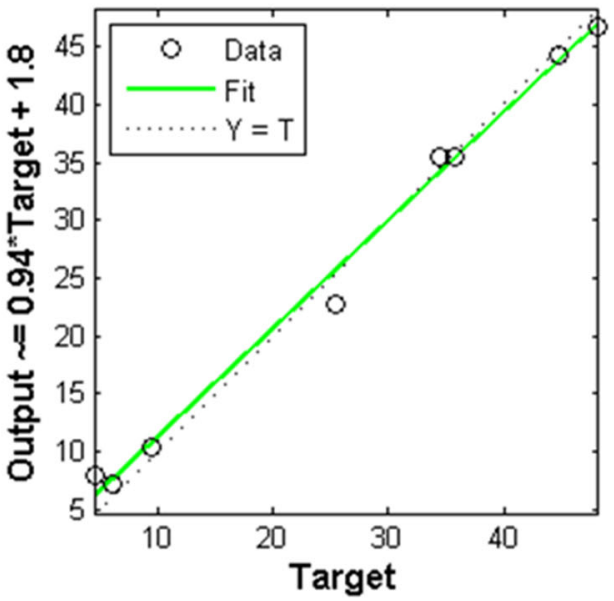

All: $\mathrm{R}=0.98894$

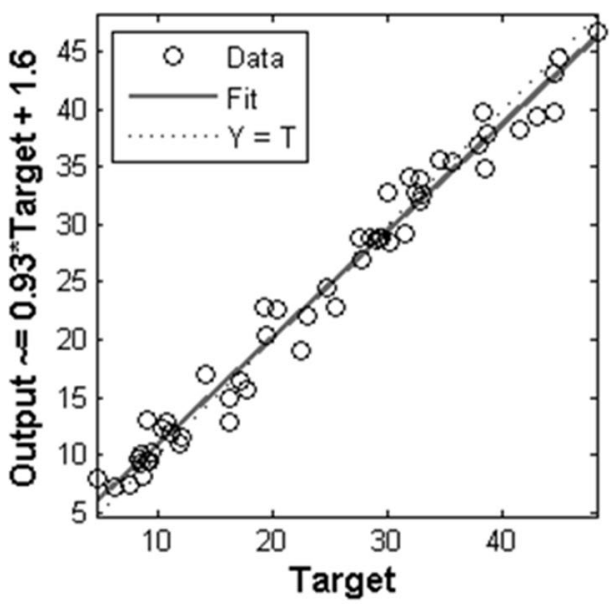

Fig. 3 Trained network for $C_{5}^{+}$selectivity data

Table 2 Analysis of variance and regression coefficient of the RSM modeling

\begin{tabular}{|c|c|c|c|c|c|c|}
\hline \multirow[t]{2}{*}{ Item } & \multicolumn{2}{|c|}{ Model for CO conversion } & \multicolumn{2}{|c|}{$\mathrm{CH}_{4}$ selectivity } & \multicolumn{2}{|c|}{$C_{5}^{+}$Selectivity } \\
\hline & $F \_$value & $P \_$value & $F_{\text {_value }}$ & $P_{\text {_value }}$ & $F_{\text {_value }}$ & $P_{\text {_value }}$ \\
\hline Model & 213.34 & $<0.0001$ & 7.21 & 0.0091 & 444.73 & $<0.0001$ \\
\hline$T(\mathrm{~K})$ & 305.16 & $<0.0001$ & 14.24 & 0.0044 & 120.64 & $<0.0001$ \\
\hline$P($ bar $)$ & 466.89 & $<0.0001$ & 1.58 & 0.2399 & 1140.29 & $<0.0001$ \\
\hline$T(\mathrm{~K}) * T(\mathrm{~K})$ & 80.98 & $<0.0001$ & 5.81 & 0.0392 & 73.28 & $<0.0001$ \\
\hline$P($ bar $) * P($ bar $)$ & 4.05 & $<0.0001$ & - & - & - & - \\
\hline$T(\mathrm{~K}) * P(\mathrm{bar})$ & - & & - & - & - & - \\
\hline$R^{2}$ & 0.99 & & 0.72 & & 0.99 & \\
\hline$R_{\text {adj }}^{2}$ & 0.98 & & 0.58 & & 0.99 & \\
\hline
\end{tabular}

RSM models used for simulation

$\mathrm{CO}$ conversion $=7174.89464-27.01005 \times$ Temperature $+3.92459 \times$ Pressure $^{+} 0.025422 \times$ Temperature $^{2}+0.22209 \times$ Pressure $^{2}$

$\mathrm{CH}_{4}$ selectivity $=2425.48936-9.06181 \times$ Temperature $-0.49879 \times$ Pressure $+8.48642 \mathrm{E}(-3) \times$ Temperature $^{2}$

$C_{5}^{+}$selectivity $=2582.30640-9.63979 \times$ Temperature $+3.99115 \times$ Pressure $+8.98494 \mathrm{E}(-3) \times$ Temperature $^{2}$ 
Table 3 The obtained RSM models in coded version

$$
\begin{aligned}
& \mathrm{CO} \text { conversion }=+39.24+10.65 \times A+13.18 \times B+3.97 \times A^{2}+0.89 \times B^{2} \\
& \mathrm{CH}_{4} \text { selectivity }=+5.13+2.99 \times A-1.00 \times B+1.33 \times A^{2} \\
& C_{5}^{+} \text {selectivity }=+21.86+2.60 \times A+7.98 \times B+1.40 \times A^{2}
\end{aligned}
$$

$A$ Temperature, $B$ Pressure
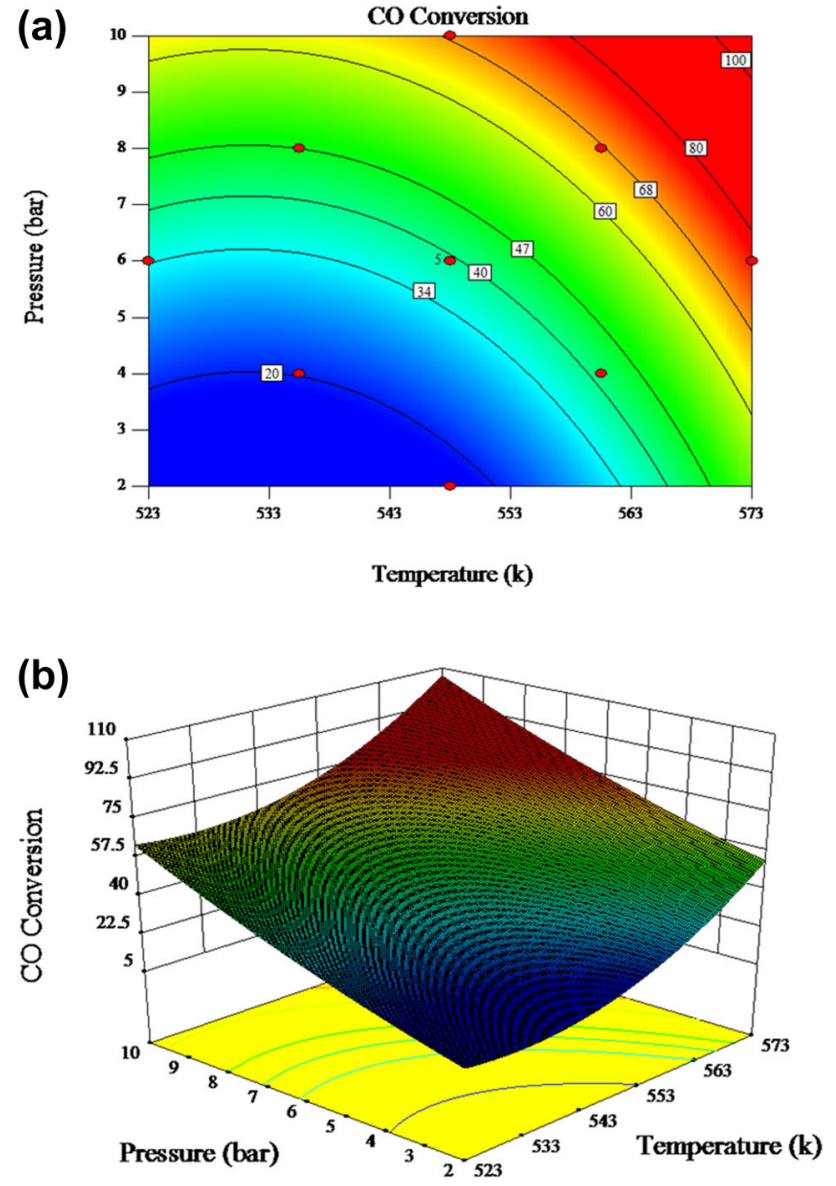

Fig. 4 Contour (a) and 3D surface (b) plots for CO conversion

\section{Conclusions}

As noted earlier, there have been few researchers who have investigated the Fischer-Tropsch products selectivity, quantitatively. The modeling of the CO conversion and hydrocarbon selectivity of the Fischer-Tropsch synthesis over $\mathrm{Fe}-\mathrm{Ni} / \mathrm{Al}_{2} \mathrm{O}_{3}$ catalyst was investigated by using coupled artificial neural networks and design of experiment. Pressure and temperature were selected as the variable parameters. ANN was employed to train networks related to original experimental data, and central composite design was used for designing of experiment in the exact range of temperature and pressure as the original operating condition. After training data by ANN and determination of DOE points by CCD, these results were combined together
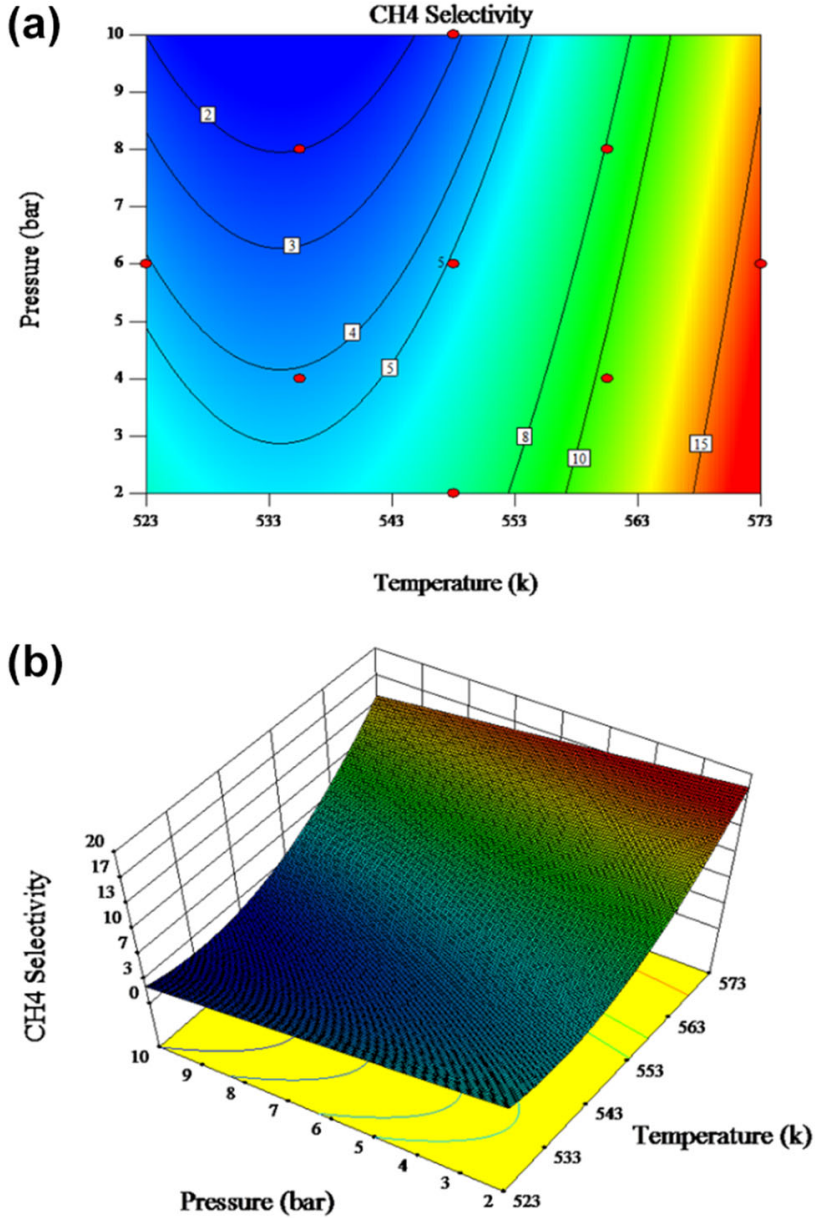

Fig. 5 Contour (a) and 3D surface (b) plots for $\mathrm{CH}_{4}$ selectivity

for producing simulated data to be used in response surface method. The approach of RSM provided the regression equations for $\mathrm{CO}$ conversion, $\mathrm{CH}_{4}$ selectivity, and $C_{5}^{+}$ selectivity according to the temperature and pressure. The analysis of variance was employed to test the significance of the parameters in the equations. The concluding equations were obtained ( $\mathrm{CO}$ conversion, $\mathrm{CH}_{4}$ selectivity, and $C_{5}^{+}$selectivity). The results illustrated that artificial neural network is a practical tool to model and estimate catalytic behavior in reactors. The results also indicated that $\mathrm{CO}$ conversion increased with an increase in both in temperature and pressure. The methane selectivity increased by increasing the temperature and decreasing pressure. The pressure possessed a positive effect on $C_{5}^{+}$selectivity at 

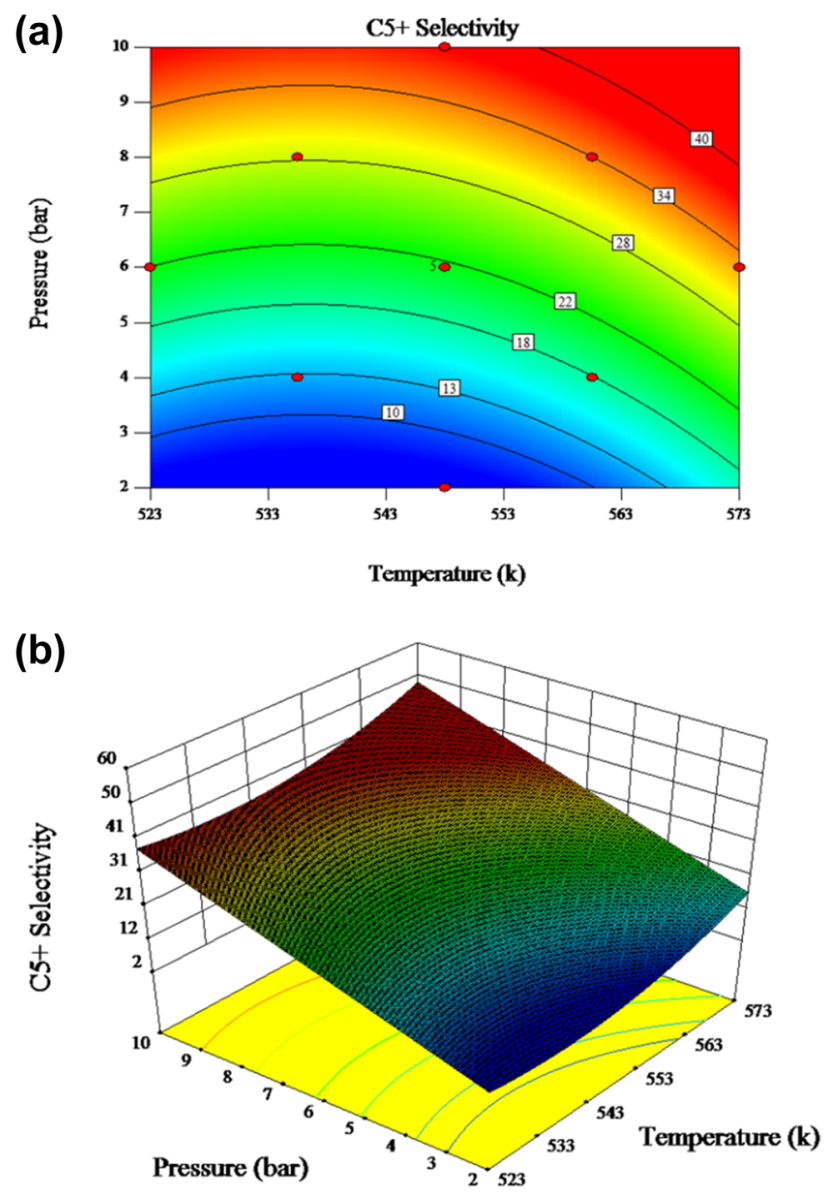

Fig. 6 Contour (a) and 3D surface (b) plots for $C_{5}^{+}$selectivity

any temperature. The $C_{5}^{+}$selectivity also remained approximately constant at low to moderate temperatures while from moderate to high temperatures, it increased with temperature. These models show how the main parameters in the process can affect the products distribution. Finally, the optimization of the products distribution, in which maximization of $C_{5}^{+}$and $\mathrm{CO}$ conversion and minimization of $\mathrm{CH}_{4}$ occurred simultaneously, was done. The optimum condition is around $T=558 \mathrm{~K}, P=8$ bar.

Open Access This article is distributed under the terms of the Creative Commons Attribution 4.0 International License (http://crea tivecommons.org/licenses/by/4.0/), which permits unrestricted use, distribution, and reproduction in any medium, provided you give appropriate credit to the original author(s) and the source, provide a link to the Creative Commons license, and indicate if changes were made.

\section{References}

Atashi H, Rezaeian F (2017) Modelling and optimization of FischerTropsch products through iron catalyst in fixed-bed reactor. Int $\mathrm{J}$ Hydrogen Energy 42:15497-15506
Atashi H, Razmjooei S, Khorashadizadeh M, Shiva M, Tabrizi FF, Mousavi SAHS (2015) Effects of operating conditions on selectivity of $\mathrm{Fe}-\mathrm{Co}-\mathrm{Mn} / \mathrm{MgO}$ at high temperature $\mathrm{CO}$ hydrogenation. J Taiwan Inst Chem Eng 54:83-90

Bashiri N, Royaee SJ, Sohrabi M (2018) The catalytic performance of different promoted iron catalysts on combined supports $\mathrm{Al}_{2} \mathrm{O}_{3}$ for carbon dioxide hydrogenation. Res Chem Intermed $44: 217-229$

Challiwala MS, Wilhite BA, Ghouri MM, Elbashir NO (2018) Multidimensional modeling of a microfibrous entrapped cobalt catalyst Fischer-Tropsch reactor bed. AIChE J 64:1723-1731

Cheng S, Zhang G, Javed M, Gao W, Mazonde B, Zhang Y, Lu C, Yang R, Xing C (2018) Solvent-free synthesis of 1D cancrinite zeolite for unexpectedly improved gasoline selectivity. ChemistrySelect 3:2115-2119

Coronel-García M, de la Torre AR, Melo-Banda J, Martínez-Salazar A, Rodrigo RS, Zavala ND, Martínez BP, Domínguez J (2015) Study of Co, Ru/SBA-15 type materials for Fischer-Tropsch synthesis in fixed bed tubular reactor: I. Effect of the high Ru content on the catalytic activity. Int $\mathrm{J}$ Hydrogen Energy 40:17264-17271

Derevich I, Ermolaev V, Mordkovich V (2012) Modeling of hydrodynamics in microchannel reactor for Fischer-Tropsch synthesis. Int J Heat Mass Transf 55:1695-1708

Farias FE, Sales FG, Fernandes FA (2008) Effect of operating conditions and potassium content on Fischer-Tropsch liquid products produced by potassium-promoted iron catalysts. J Nat Gas Chem 17:175-178

Feyzi M, Khodaei MM, Shahmoradi J (2015) Preparation and characterization of promoted Fe-Mn/ZSM-5 nano catalysts for CO hydrogenation. Int J Hydrogen Energy 40:14816-14825

Fu T, Jiang Y, Lv J, Li Z (2013) Effect of carbon support on FischerTropsch synthesis activity and product distribution over Cobased catalysts. Fuel Process Technol 110:141-149

Ishihara T, Eguchi K, Arai H (1987) Hydrogenation of carbon monoxide over $\mathrm{SiO}_{2}$-supported $\mathrm{Fe}-\mathrm{Co}, \mathrm{Co}-\mathrm{Ni}$ and $\mathrm{Ni}-\mathrm{Fe}$ bimetallic catalysts. Appl Catal 30:225-238

Khodakov AY, Chu W, Fongarland P (2007) Advances in the development of novel cobalt Fischer-Tropsch catalysts for synthesis of long-chain hydrocarbons and clean fuels. Chem Rev 107:1692-1744

Li T, Wang H, Yang Y, Xiang H, Li Y (2014) Study on an iron-nickel bimetallic Fischer-Tropsch synthesis catalyst. Fuel Process Technol 118:117-124

Liu R-J, Xu Y, Qiao Y, Li Z-H, Ma X-B (2015) Factors influencing the Fischer-Tropsch synthesis performance of iron-based catalyst: iron oxide dispersion, distribution and reducibility. Fuel Process Technol 139:25-32

Mirzaei AA, Kiai RM, Atashi H, Arsalanfar M, Shahriari S (2012) Kinetic study of CO hydrogenation over co-precipitated ironnickel catalyst. J Ind Eng Chem 18:1242-1251

Najafabadi AT, Khodadadi AA, Parnian MJ, Mortazavi Y (2016) Atomic layer deposited $\mathrm{Co} / \gamma-\mathrm{Al}_{2} \mathrm{O}_{3}$ catalyst with enhanced cobalt dispersion and Fischer-Tropsch synthesis activity and selectivity. Appl Catal A 511:31-46

Nasr N, Hafez H, ElNaggar MH, Nakhla G (2013) Application of artificial neural networks for modeling of biohydrogen production. Int J Hydrogen Energy 38:3189-3195

Park N, Kim J-R, Yoo Y, Lee J, Park M-J (2014) Modeling of a pilotscale fixed-bed reactor for iron-based Fischer-Tropsch synthesis: two-dimensional approach for optimal tube diameter. Fuel 122:229-235

Parnian MJ, Khodadadi AA, Najafabadi AT, Mortazavi Y (2014a) Preferential chemical vapor deposition of ruthenium on cobalt with highly enhanced activity and selectivity for FischerTropsch synthesis. Appl Catal A 470:221-231 
Parnian MJ, Najafabadi AT, Mortazavi Y, Khodadadi AA, Nazzari I (2014b) $\mathrm{Ru}$ promoted cobalt catalyst on $\gamma-\mathrm{Al}_{2} \mathrm{O}_{3}$ : influence of different catalyst preparation method and $\mathrm{Ru}$ loadings on Fischer-Tropsch reaction and kinetics. Appl Surf Sci 313:183-195

Peña D, Jensen L, Cognigni A, Myrstad R, Neumayer T, Van Beek W, Rønning M (2018) The effect of copper loading on iron carbide formation and surface species in iron-based FischerTropsch synthesis catalysts. ChemCatChem 10:1300-1312

Pirdashti M, Curteanu S, Kamangar MH, Hassim MH, Khatami MA (2013) Artificial neural networks: applications in chemical engineering. Rev Chem Eng 29:205-239

Ralston WT, Melaet G, Saephan T, Somorjai GA (2017) Evidence of structure sensitivity in the Fischer-Tropsch reaction on model cobalt nanoparticles by time-resolved chemical transient kinetics. Angew Chem Int Ed 56:7415-7419

Rodríguez-Fernández J, Tsolakis A, Cracknell R, Clark R (2009) Combining GTL fuel, reformed EGR and HC-SCR aftertreatment system to reduce diesel $\mathrm{NO}_{\mathrm{x}}$ emissions. A statistical approach. Int J Hydrogen Energy 34:2789-2799

Savost'yanov A, Narochnyi G, Yakovenko R, Mitchenko S, Zubkov I (2018) Enhancement of the Fischer-Tropsch process for producing long-chain hydrocarbons on a cobalt-alumina-silica gel catalyst. Pet Chem 58:76-84
Shojaeimehr T, Rahimpour F, Khadivi MA, Sadeghi M (2014) A modeling study by response surface methodology (RSM) and artificial neural network (ANN) on $\mathrm{Cu}^{2+}$ adsorption optimization using light expended clay aggregate (LECA). J Ind Eng Chem 20:870-880

Sun Y, Yang G, Sun G, Sun Z, Zhang L (2018) Performance study of stirred tank slurry reactor and fixed-bed reactor using bimetallic Co-Ni mesoporous silica catalyst for Fischer-Tropsch synthesis. Environ Prog Sustain Energy 37:553-561

Todic B, Mandic M, Nikacevic N, Bukur DB (2018) Effects of process and design parameters on heat management in fixed bed Fischer-Tropsch synthesis reactor. Korean J Chem Eng 35(4):875-889

van Helden P, van den Berg J-A, Petersen MA, van Rensburg WJ, Ciobîcă IM, van de Loosdrecht J (2017) Computational investigation of the kinetics and mechanism of the initial steps of the Fischer-Tropsch synthesis on cobalt. Faraday Discuss 197:117-151

Yang J-I, Yang JH, Kim H-J, Jung H, Chun DH, Lee H-T (2010) Highly effective cobalt catalyst for wax production in FischerTropsch synthesis. Fuel 89:237-243

Zhang H, Yuanyi Y, Wei D, Shuliang L, Haibo Y, Yuanyuan J (2014) Size-controlled $\mathrm{Pd}$ nanoparticles supported on $\alpha-\mathrm{Al}_{2} \mathrm{O}_{3}$ as heterogeneous catalyst for selective hydrogenation of acetylene. Chin J Chem Eng 22:516-521 